\title{
La disputa por el significado del marxismo: Héctor P. Agosti y las izquierdas peronistas
}

\author{
The Dispute on the Signification of Marxism: Hector P. Agosti and the \\ Peronist Leftists
}

Martín Gerlo*

\begin{abstract}
Resumen: El presente trabajo pretende reconstruir las formulaciones elaboradas por el intelectual comunista argentino Héctor P. Agosti en el período comprendido entre 1956 - meses después del golpe que derrocó al presidente Juan Domingo Perón- y el proceso electoral desarrollado en 1962, signado por fervorosos y fértiles debates en el campo de las izquierdas. Durante estos años Agosti no sólo producirá sus trabajos más relevantes, sino que también desencadenará una renovación en el ámbito cultural comunista favorecida por sus novedosos planteos teóricos inspirados en las por entonces poco conocidas ideas de Gramsci. Sus debates con diversos exponentes de las izquierdas peronistas y la izquierda nacional, no siempre amistosos pero muchas veces ricos en coincidencias, constituyeron un interesante aspecto de su producción teórico-política que se vuelve necesario recuperar para dar una imagen más completa de sus aportes.
\end{abstract}

Palabras clave: Agosti, intelectuales, comunismo, peronismo, marxismo

\begin{abstract}
This work intends to reconstruct the formulations elaborated by the Argentinian communist thinker Héctor P. Agosti during the period between 1956 - months after the coup which deposed president Juan Domingo Perón - and the poll process that took place during 1962, marked by passionate and fruitful debates in the leftist political field. In these years, Agosti not only produced his most relevant works, but he also triggered a renewal in the communist cultural field, favoured by his novel theoretical poses inspired by Gramsci's ideas, not by then so well known. His debates with different figures of the peronist and the national lefts, not always friendly but frequently rich in coincidences. constituted an interesting aspect of his theoretical-political production, which is necessary to recover to provide a more complete idea of his contributions.
\end{abstract}

Keywords: Agosti, thinkers, communism, peronism, marxism.

Recibido : 12 mayo 2016

Aceptado : 23 julio 2016

\footnotetext{
* Argentino, Licenciado en Comunicación Social, Universidad Nacional de Entre Ríos (UNER). Contacto: martingerlo@gmail.com.
} 


\section{Introducción}

Lejos de la homogeneidad y rigidez con que suele presentárselo, el campo cultural comunista tuvo diversas y significativas manifestaciones que desafiaron la ortodoxia y propiciaron la relectura y reelaboración de sus propios supuestos, cuya legitimidad era constantemente puesta en cuestión por grupos intelectuales que, tras el derrocamiento y la posterior proscripción del peronismo, iban ganando adhesión y difusión en las capas medias y sectores de izquierda desencantados con los exponentes tradicionales de esa tendencia. Si bien es atinado afirmar que las rupturas juveniles de la década del 60 se explican en gran medida por las dificultades que mostró el Partido Comunista Argentino (PCA) para actualizar sus postulados políticos y filosóficos, incorporando los aportes que cuestionaban frontal o tangencialmente el DIAMAT soviético y las rémoras liberales que asfixiaban la potencialidad creadora del marxismo, ese postulado es incorrecto si no se tienen a su vez en cuenta los debates y reflexiones que, sin alcanzar a trastocar completamente la línea política defendida por la conducción, generaron una importante experiencia de renovación en el ámbito cultural, sentando las bases y generando en alguna medida las condiciones para que posteriormente surjan nuevos grupos y se produzcan las escisiones más conocidas ${ }^{1}$.

La imagen de una intelectualidad comunista sorda a los reclamos de sus bases, las emergentes formaciones culturales y las nuevas elaboraciones teóricas constituye una equiparación no pocas veces injusta entre su rol histórico y el que paralelamente jugaron los principales cuadros de la dirección partidaria, a quienes tal vez sí puedan corresponderles de esas objeciones. Esta indiferenciación puede desandarse dejando de lado el rígido concepto de aparato cultural, como extensión sin mediaciones de la esfera estrictamente política a la actividad cultural, por el más complejo y flexible de campo, tal como sugeríamos más arriba, donde se pueden apreciar con mayor precisión los diversos grados de autonomía relativa existentes entre ambas manifestaciones. Esta prevención metodológica basada en conceptos de Pierre Bourdieu la tomamos en la misma forma que es adoptada por Néstor Kohan ${ }^{2}$, quien promueve un acercamiento más preciso a las complejas relaciones entre diversos actores y a los criterios de legitimidad propios de cada campo. A su vez, dentro del propio campo cultural comunista convivieron distintas personalidades que merecerían un tratamiento diferenciado y en profundidad, de acuerdo a los diversos modos en que cada uno de ellos buscó dar respuesta a los problemas que se les presentaban, a sus contactos con intelectuales de otras filiaciones políticas y a su no siempre pacífica relación con la conducción partidaria, encarnada fundamentalmente en Victorio Codovilla.

Siguiendo este planteo, resulta de gran interés volver sobre el pensamiento y la acción de Héctor P. Agosti, analizando sus trabajos en el convulsionado y prolífico período comprendido entre la caída de Perón y el apoyo brindado por el PCA a los candidatos de su

\footnotetext{
${ }^{1}$ De todas ellas posiblemente la más relevante fue aquella que se produjo en 1963 con los integrantes de la revista Pasado y Presente, cuyos principales exponentes eran José María Aricó y Juan Carlos Portantiero, ex discípulos de Agosti.

${ }^{2}$ KOHAN, Néstor. Ni calco ni copia. Ensayos sobre el marxismo argentino y latinoamericano, Cuba. URL: http://lahaine.org/amauta/b2-img/nestor_calco.pdf. La versión argentina de esta obra se titula De Ingenieros al Che. Ensayos sobre el marxismo argentino y latinoamericano, y fue editada en el año 2000 por la Editorial Biblos.
} 
fuerza política en 1962, momento en el cual cobró fuerzas entre el comunismo la teoría del "giro a la izquierda" del movimiento peronista, lectura propiciada por circunstancias históricas y, a nuestro criterio, por aportes conceptuales como los que venía desarrollando Agosti. Su rol como director de la revista Cuadernos de cultura (la más importante publicación partidaria en ese entonces), como así también de escritor y editor, lo ubicaron en un lugar privilegiado dentro de la producción intelectual y los debates políticos entablados hacia el interior del comunismo, pero también respecto a pensadores de otras procedencias políticas. Una de sus principales inquietudes en aquellos años fue actualizar las bases filosóficas de su partido, incorporando nuevas elaboraciones teóricas - fundamentalmente los imprescindibles aportes de Gramsci al pensamiento marxista - y saldando cuentas con la tradición liberal argentina, cuyos vínculos con el ideario del comunismo argentino fueron tensos y estrechos. A la vez que esta tarea tenía lugar, los intelectuales del PCA, con Agosti a la cabeza, ensayaron una fuerte defensa frente a las nuevas izquierdas en ascenso, peronistas y no peronistas, buscando conservar una legitimidad que les era permanentemente disputada y puesta en cuestión, fundamentalmente dentro de los sectores juveniles y progresistas. En ese sentido, aquí nos proponemos analizar la producción teórica y la acción política de Agosti frente a lo que por esos años llamó "neoizquierda", una distinción imprecisa entre diversas tendencias no siempre desarticuladas pero sí distinguibles, dentro de las cuales debemos resaltar a la Izquierda Nacional, cuyo máximo exponente fue Jorge Abelardo Ramos, y a las expresiones de la izquierda peronista representadas principalmente por Juan José Hernández Arregui, John William Cooke y Rodolfo Puiggrós, el único de ellos con pasado comunista. Consideramos que algunas definiciones sobre diversas izquierdas, esbozadas en su momento por los mismos actores de los debates y cristalizadas posteriormente en algunas construcciones historiográficas, levantaron barreras que no propiciaron una lectura más amplia respecto a coincidencias, intercambios y disputas entre pensadores de distintas tendencias. Sin relegar las clasificaciones, que bien utilizadas tienen un valor analítico importante, nos proponemos mostrar que la producción teórica de Agosti en los años expuestos alcanzan un importante grado de elaboración que lo conduce a acercamientos nada desdeñables con intelectuales de las izquierdas peronistas.

Diversos trabajos y artículos que nos sirvieron de fuente o punto de partida han abordado esta problemática o aspectos parciales de ella. Entre las principales contribuciones a la reconstrucción del pensamiento de Agosti cabe destacar el libro de Alexia Massholder El Partido Comunista y sus intelectuales. Pensamiento y acción de Héctor P. Agosti, como así también la tesis de maestría de Laura Prado Acosta, Héctor Agosti, el difícil equilibrio. Itinerario de un intelectual orgánico del Partido Comunista Argentino (1935-1963), ambos trabajos de publicación reciente. El libro de Néstor Kohan De Ingenieros al Che. Ensayos sobre el marxismo argentino y latinoamericano dedica un interesante capítulo a la trayectoria particular de Agosti, igual que respecto a otros pensadores de la izquierda comunista (Giúdici) o peronista (Cooke, Hernández Arregui o Puiggrós) que sirven para reconstruir algunos debates. El Diccionario biográfico de la izquierda argentina. De los anarquistas a la "nueva izquierda" (1870-1976), de Horacio Tarcus, constituye un insustituible material de consulta para la búsqueda y corroboración de información sobre cada uno de los pensadores y militantes de la izquierda argentina mencionados en este artículo. Entre los trabajos ya clásicos que abordan la cuestión general 
de los intelectuales de izquierda y su relación con el peronismo cabe destacar la obra de Oscar Terán, Nuestros años sesenta. La formación de la nueva izquierda intelectual argentina y la de Carlos Altamirano, Peronismo y cultura de izquierda ${ }^{3}$. Es necesario señalar que la biblioteca personal de Agosti, junto a publicaciones históricas del PCA y material aún inédito sobre el intelectual comunista, se encuentra en el Centro de Formación Marxista que lleva su nombre, en la ciudad de Buenos Aires, y cuya directora es Alexia Massholder, quien nos permitió acceder a esos archivos y constituyó una fuente permanente de consulta para este trabajo.

\section{Los intelectuales comunistas tras la caída de Perón}

Pocos meses después del golpe de Estado que derrocó al gobierno constitucional de Perón, frente al cual la política comunista había sido cambiante y adoptó distintas posturas ${ }^{4}$, Agosti redacta el informe que leería ante la primera conferencia nacional de intelectuales comunistas, cuya realización estaba prevista para los últimos días de marzo de 1956. En ese trabajo, que finalmente no pudo exponerse debido a la suspensión de la actividad por "razones de seguridad y orden público", pero fue que editado el mismo año, el principal responsable de los temas culturales del PCA analizaba los problemas que configuraban la "crisis de la sociedad argentina" tras los diez años de "dictadura justicialista" y la reciente "euforia provocada por su caída". En ese sentido, aun conservando su juicio negativo sobre el líder del movimiento peronista, señalaba que "para que la demagogia haya podido prosperar debieron existir en la sociedad argentina algunas causas, algunos problemas irresueltos que le dieran fundamento", ya que ella estuvo afirmada en "la explotación de profundas necesidades del pueblo argentino" . Esta posición, fuertemente condenatoria de la figura de Perón y lejos aún de la crítica profunda al liberalismo que venía elaborando y publicará tres años después, sienta las bases para un análisis distinto al que por entonces desarrollaban los círculos liberales antiperonistas y marcará el pulso de sus afirmaciones posteriores. ¿Cuáles eran las causas que habían posibilitado la experiencia peronista, cuya persistencia iba evidentemente más allá de las críticas — más morales que políticasrespecto a la "demagogia" del líder popular derrocado? Este punto, aun con el discreto énfasis con que se enunciaba y todas las prevenciones al respecto, ya había generado un punto de distanciamiento importante entre Agosti y los intelectuales liberales con quienes había compartido la Campaña Echeverriana en 1951. Esta experiencia había buscado agrupar a todo el frente de intelectuales antiperonistas en ocasión del centenario de la

\footnotetext{
${ }^{3}$ Los datos completos de todas estas obras pueden encontrarse en el apartado final.

${ }^{4} \mathrm{Si}$ bien excede los límites de este trabajo, es importante remarcar que las posturas del PCA frente al peronismo estuvieron lejos de ser estáticas, como pretende cierta historiografía que congela el primer momento de rechazo absoluto frente al "Nazi-peronismo" e ignora los vaivenes posteriores. Una interesante periodización al respecto puede hallarse en GURBANOV, A. y RODRÍGUEZ, S., "La compleja relación entre el Partido Comunista Argentino y el peronismo: (1943 - 1955)", Primer Congreso de Estudios sobre el Peronismo, Mar del Plata, noviembre 2008. Los autores fijan allí seis períodos por los cuales pasó la relación entre ambas fuerzas entre 1943 y 1955: la mencionada del comienzo, el balance tras la derrota electoral y nueva estrategia, un nuevo período de críticas en tiempos de la reforma constitucional, un nuevo giro hacia 1951, el momento signado por el "Caso Real” a partir de 1953 y por último las posiciones tras los bombardeos y el golpe de 1955 .

5 AGOSTI, Héctor P. Para una política de la cultura. Buenos Aires, Procyón, 1956, pág. 9.
} 
muerte de Esteban Echeverría, una efeméride que, como todas las construcciones históricas, respondía más a exigencias políticas del presente (constituir un bloque opositor a las políticas culturales e historiográficas del peronismo) que a una desinteresada reivindicación del autor de Dogma socialista, aunque en el caso particular de Agosti este rescate estaría presente durante toda su vida. Las diferencias de criterios fueron resquebrajando rápidamente el frente hasta precipitar su ruptura, dando lugar a dos espacios: ASCUA (Asociación Cultural para la Defensa y Superación de Mayo), donde abrevaron los liberales, y Casa de la Cultura Argentina, que reagrupó a los comunistas ${ }^{6}$.

Para Agosti, el antiimperialismo del "líder depuesto", aun cuando lo catalogaba como "declamatorio" y lo encerraba entre comillas, había podido prosperar porque existía en las masas "un hondo sentimiento de la opresión imperialista", del mismo modo que la "declamación de la 'justicia social' (nuevamente entre comillas) pudo prosperar inicialmente porque también las masas tienen conciencia de la sofocación en que las mantiene la oligarquía y el gran capital'. Siguiendo los planteos habituales de su partido, el autor de Defensa del realismo insistía en que la solución de fondo se hallaba en la realización de la "revolución democráticoburguesa, conducida por la clase obrera y su partido de vanguardia, que en las condiciones argentinas asume - necesariamente-

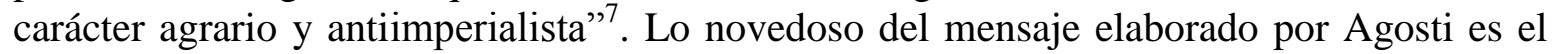
análisis del rol de los intelectuales en el proceso de liberación nacional, una tenue reivindicación de todas las "clases y grupos nacionales" y la afirmación de una correspondencia entre socialismo y nacionalidades, intentando desandar el tan mentado internacionalismo del que se acusaba a los comunistas: "El marxismo sólo podrá sernos útil si adquiere una forma nacional, es decir, si se aplica al examen concreto y original de los fenómenos argentinos"

Tras esta afirmación, Agosti insistirá en el llamado a llevar adelante la "lucha ideológica" para la cual es imprescindible establecer alianzas con otros sectores, haciendo en esa línea dos llamados de atención importantes. En primer lugar, esa lucha no deberá consistir "en una denuncia pura y simple de todos los sabios y filósofos no marxistas, ni en una repetición abstracta y monótona del abecé del marxismo". Aunque pueda parecer un alegato débil, este pasaje cuestiona a la ortodoxia y su filosofía oficial, que por entonces obturaba cualquier posibilidad de una necesaria renovación teórica y política. Esa afirmación iba acompañada en segundo término por una advertencia que tomaba la forma de una profunda autocrítica:

Para convencer de la justicia de nuestros argumentos necesitamos dialogar, y para dialogar es preciso despojarnos de esa jactancia que pareciera investirnos de todas las perfecciones, como si el carnet del partido confiriera automáticamente talento, como si nosotros no nos equivocáramos nunca, como si a veces no nos correspondiera alguna culpa en el empeoramiento de las cosas. ${ }^{9}$

\footnotetext{
${ }^{6}$ A pesar de la ruptura, Agosti siguió siempre de cerca la trayectoria que tomaron sus ex compañeros, a punto tal que les dedicó un extenso artículo donde ajusta cuentas con ellos tras la ruptura de ASCUA, producida en 1962. Esta crítica a la intelectualidad liberal, titulada "La inteligencia inhábil", puede encontrarse en el número 58 de la revista Cuadernos de cultura, junio-julio de 1962.

${ }^{7}$ AGOSTI, Héctor. Op. Cit., págs. 10-11.

${ }^{8}$ Ibídem, pág. 31.

${ }^{9}$ Ibídem, pág. 39.
} 
Sin extraer todas las consecuencias de esa necesaria prevención, que tal vez lo hubiera conducido a una autocrítica más amplia y extendida, Agosti tiende un puente para dialogar con las "clases y grupos nacionales" señalados anteriormente, que aunque no los nombre puntualmente incluían al peronismo y las nuevas izquierdas emergentes ${ }^{10}$. Luego de ese pasaje, y no casualmente, recomendaba a sus pares la lectura de Gramsci, "cuyos cuadernos conviene releer constantemente" ya que a su juicio constituyen "uno de los modelos más eminentes de la crítica marxista"11. Cabe destacar que por entonces los Cuadernos de la cárcel del pensador italiano no habían sido traducidos y editados en español, tarea que impulsará recién dos años después el propio Agosti desde la Editorial Lautaro, la cual ya en 1950, tan sólo tres años después de la primera edición en su idioma original, había publicado las Cartas desde la cárcel. En esa línea, es importante resaltar que más allá de las traducciones y las ediciones en español de los hasta entonces casi desconocidos trabajos del intelectual italiano, Agosti haría un uso práctico de algunas categorías analíticas de los Cuadernos en sus propios trabajos, fundamentalmente el Echeverría. Néstor Kohan señalará en este sentido que "la verdadera recepción productiva de Gramsci (en la Argentina) comienza con el Echeverría de Agosti" ". A pesar de las críticas que realiza sobre ese mismo libro, el propio José Aricó subrayó también la influencia gramsciana en este trabajo: "Su ensayo sobre Echeverría constituye acaso el ejemplo más acabado - y visto desde el presente, el más emblemático - de una forma de proceder con los textos gramscianos"13. El concepto gramsciano fundamental que opera como clave de lectura en ese libro de Agosti es el de revolución interrumpida o incumplida, en el caso argentino aplicado a la Revolución de Mayo de 1810, y hablará de los “jacobinos" de ese país tomando prestado el sentido que le da Gramsci al término ${ }^{14}$.

En los meses posteriores al derrocamiento de Perón, mientras la dictadura comenzaba a mostrar su rostro liberal y represivo — materializado principalmente en constantes encarcelamientos y los fusilamientos en el basural de José León Suárez-, se produce un hecho que dejaría una huella profunda en la historia mundial de los comunistas. El XX Congreso del Partido Comunista de la Unión Soviética (PCUS), celebrado entre el 14 y 26 de febrero, había dado a conocer un informe donde se exponían los "abusos de poder y crímenes" que tuvieron lugar en ese país bajo la conducción de Stalin, quien había muerto en 1953. Esta revelación, según reconstruye Alexia Massholder, generó un profundo "desconcierto" que dio lugar a "fuertes debates" dentro de las filas partidarias, y

\footnotetext{
${ }^{10}$ Una actitud similar puede apreciarse en un artículo de 1953 donde Agosti escribe la crítica a un trabajo reciente del filósofo Carlos Astrada, quien simpatizaba políticamente con el peronismo. El acercamiento al marxismo por parte de Astrada y su propensión al diálogo es calificado como una "señal auspiciosa" por parte de Agosti, quien agrega: "Y creemos que el diálogo podrá ensancharse, y tornarse más valedero y fecundo, si se lo prosigue sobre el vasto escenario de la acción práctica, donde es preciso que coincidan en nuestro país todos quienes, de una u otra manera, se sientan empujados a preparar los caminos para el humanismo de la libertad real y no simplemente declamada". AGOSTI, Héctor P. Prosa política. Buenos Aires, Editorial Cartago, 1975.

${ }^{11}$ Agosti, Héctor P. Para una política de la cultura, op. cit., pág. 40.

${ }^{12}$ KOHAN, op. cit., pág. 220

${ }^{13}$ ARICÓ, José M. La cola del diablo. Itinerario de Gramsci en América Latina. Buenos Aires, Siglo XXI, 2014., pág. 50.

${ }^{14}$ AGOSTI, Héctor P. Echeverría, Buenos Aires, Editorial Futuro, 1951, pág. 43.
} 
aunque las consecuencias que tuvo son difíciles de establecer, algunos testimonios dan la pauta de que el informe produjo un gran desencanto en al menos un sector la militancia comunista argentina ${ }^{15}$. Néstor Kohan, por su parte, considera que ese acontecimiento daría inicio "sólo formalmente" a la desestalinización en el PCA, y que los límites impuestos por la ortodoxia siguieron siendo muy rígidos durante los años posteriores. Ambos puntos de vista pueden haber sido compatibles, existiendo una autocrítica y proceso parcial de renovación restringido al plano cultural y a las discusiones intrapartidarias, a la vez que las decisiones políticas tomadas por la conducción siguieron inflexibles en su cerrazón dogmática. Posiblemente esa ambivalencia fue uno de los dramas que terminaría marcando el trabajo intelectual encarado en aquellos años por Agosti.

\section{La renovación teórica}

Mientras en el plano político comienzan a gestarse los acontecimientos que llevaron al poder al radical Arturo Frondizi — quien rápidamente dejaría de lado el programa que había suscitado el apoyo a su candidatura por parte de peronistas, comunistas y sectores de izquierda independiente-, Agosti inaugura el más rico y prolífico período de su vida intelectual, con la edición de los Cuadernos de la cárcel de Gramsci y la publicación de dos de sus trabajos más importantes: Nación y cultura y El mito liberal.

En 1958 saldrá la edición en español de El materialismo histórico y la filosofía de Benedetto Croce, el primero de los seis libros que constituyen la edición temática de los Cuadernos del intelectual italiano, cuyo prólogo estuvo a cargo de Agosti mientras que la traducción fue realizada por Isidoro Flaumbaun. Esa tarea se completaría con Los intelectuales y la organización de la cultura (1960, traducción de Raúl Sciarreta), Literatura y vida nacional (1961, traducción de José Aricó y prólogo de Agosti) y La política y el Estado moderno (1962, traducción y prólogo de Aricó), todos ellos editados por la Editorial Lautaro. Esta apuesta puede comprenderse íntegramente sólo si se la mira más allá del simple episodio editorial, tomando en cuenta la labor de promoción de las ideas de Gramsci y su aplicación en las elaboraciones teóricas sobre la realidad política argentina que Agosti venía realizando ya desde principios de esa década, primero con la edición de las Cartas, casi al mismo tiempo con la escritura de Echeverría, luego con la recomendación de su lectura a sus pares y ahora con la publicación de los textos carcelarios.

En una escena marcada por la fuerte peronización de los sectores obreros, el ámbito cultural seguía siendo el espacio donde mayor gravitación podían alcanzar los planteos elaborados desde el comunismo, que comenzaba a tener más en cuenta las causas que daban lugar a esa persistencia identitaria ${ }^{16}$. La condicionada apertura que posibilitaba el

\footnotetext{
15 MASSHOLDER, Alexia. El Partido Comunista y sus intelectuales: pensamiento y acción de Héctor P. Agosti, Buenos Aires, Luxemburg, 2014, pág. 213. En este pasaje, la autora transcribe un fragmento de la entrevista realizada a Roberto Socolovsky, un militante de aquellos años: "Fue como si parte de nuestra vida y de nuestro esfuerzo y de nuestra militancia se va a la basura; entonces es preferible no contabilizar todo eso".

16 “Entre 1955 y 1958 los comunistas se empeñarán en una táctica destinada a ordenar las fuerzas en términos políticos que escaparan al eje peronismo/antiperonismo. A su modo, ellos también aguardaban que el nuevo orden trajera la 'liberación' al mundo peronista. No obstante, al igual que los socialistas habrán de encontrarse con que el 'muro de contención' desatará, en efecto, la acción de las masas, pero no las desprenderá de la
} 
proceso de desestalinización confluía con este fenómeno de orden local: la radicalización de la clase trabajadora que, a pesar de la proscripción del movimiento en que se enrolaba mayoritariamente, continuaba mostrando hacia él un profundo sentido de pertenencia. Esto generará las condiciones para que la relectura de la situación argentina contemporánea traiga consigo una imprescindible resignificación de muchos supuestos históricos, asentados en la construcción liberal que hasta entonces sólo había sido cuestionada de manera frontal por el revisionismo clásico, impregnado de una lectura orientada hacia un nacionalismo conservador o de derechas. Desde posiciones cercanas al peronismo y el marxismo surgieron entonces importantes obras de reinterpretación histórica que cuestionaban severamente los supuestos liberales y se distanciaban a su vez de ese revisionismo: en 1956 aparece Historia crítica de los partidos políticos argentinos, de Puiggrós ${ }^{17}$, mientras que al año siguiente lo hacen Revolución y contrarrevolución en la Argentina, de Ramos, e Imperialismo y Cultura, de Hernández Arregui. Estas obras, publicadas en un período de gran efervescencia política y cultural, condicionarán sin duda el cuadro de las izquierdas argentinas, generando un nuevo clima político-intelectual.

Quien desde el comunismo emprenderá la crítica más profunda hacia el liberalismo será Agosti, encarando una trabajosa construcción cuyo empeño adicional se explica en la importante gravitación que los supuestos historiográficos de esa escuela habían alcanzado a través de un largo período entre sus camaradas. Mientras las izquierdas peronistas podían despegarse de aquellos supuestos sin mayores esfuerzos y de un plumazo, dado el carácter antiliberal y la ausencia de vínculos estrechos con el liberalismo que había caracterizado al movimiento, la misma tarea en el caso de un militante del PCA debía mostrar costados casi quirúrgicos y presentaba mayores inconvenientes. En este sentido, los dos libros de Agosti publicados en 1959 pueden considerarse, aun atendiendo a las diferencias de estilo, como parte de un único proyecto: efectuar el tiro de gracia que despoje de una vez por todas a los comunistas de su liberalismo residual, ubicándolos como continuadores de la tradición democrática argentina que se hallaría en una posición equidistante entre el nacionalismo de derecha y el liberalismo conservador. Así, en Nación y cultura buscará recurrentemente a Gramsci, polemizará no sin reconocer aciertos con un representante de la izquierda peronista como Hernández Arregui, criticará al nacionalismo (desde sus exponentes más reaccionarios hasta los más populares como Fermín Chávez, Manuel Gálvez o Raúl Scalabrini Ortíz) y ajustará cuentas con algunos de los escritores más representativos de los círculos liberales ${ }^{18}$.

lealtad a Perón.” ALTAMIRANO, Carlos. Peronismo y cultura de izquierda, Buenos Aires, Siglo XXI, 2011, págs. 65-66.

${ }^{17}$ A ese trabajo, cuya reconstrucción histórica llega a 1930, se sumará luego El proletariado argentino en la revolución nacional, de 1958. Ambos serán reelaborados y pasarán a conformar una sola obra en las ediciones posteriores de Historia crítica de los partidos políticos argentinos. ALTAMIRANO, Carlos. Op. Cit., págs. 81-82.

${ }^{18}$ Uno de los interlocutores predilectos en esta confrontación, tanto para Agosti como para otros escritores como Hernández Arregui o Ramos, será Ernesto Sabato, tal vez quien simbolizaba con mayor claridad la ruptura en los círculos liberales que se produjo tras el golpe de la Revolución Libertadora. Sus denuncias a la falta de libertades del régimen "libertador", al que adhirió tempranamente, su polémica con Borges y su reinterpretación del peronismo (cuestionando al líder al tiempo que defendía a la clase obrera peronista) propiciaron un breve pero importante acercamiento con pensadores antiliberales. 
De este modo, Agosti se empeñará en disociar una tradición democrática que, al igual que la liberal pero distanciándose de ella, sería la legítima heredera de la Revolución de Mayo, contando entre sus principales exponentes a los escritores de la Generación del 37. Cabe destacar en este plano los aportes que en la misma línea venía haciendo Amaro Villanueva, escritor comunista entrerriano que también realizó valiosas observaciones sobre la poética y política en Echeverría, José Hernández y otros escritores decimonónicos que forjaron una no suficientemente explorada línea nacional, popular y democrática en el plano literario ${ }^{19}$. Como continuadores de esa interrumpida línea histórica se ubicarían los comunistas, quienes podían contrastar esas figuras al Rosas reivindicado por los nacionalistas y a los próceres construidos por la historia oficial, propiedad de los liberales. Pero, al mismo tiempo que Agosti profundizaba este trabajo historiográfico, debía avanzar sobre uno de los tópicos por el que más eran criticados los comunistas por parte de los pensadores nacionalistas, tanto de izquierda como de derecha: una injustificable ausencia de la "cuestión nacional" en sus planteos teóricos, que en el plano político se traducía en la incomprensión plena del drama argentino en tanto país semicolonial condicionado por las potencias imperialistas. Estas objeciones lograron arraigarse omitiendo ciertos matices y soslayando algunos antecedentes importantes, como las elaboraciones de Ernesto Giudici en Imperialismo inglés y revolución nacional (1940) y las del propio Puiggrós cuando aún integraba las filas comunistas. El problema estaba muy lejos de circunscribirse al ámbito filosófico y requería ser revisado de manera urgente, ya que allí se jugaban nada menos que los posicionamientos que debían adoptar ante los movimientos de liberación en los países coloniales y semicoloniales, entre los cuales la Revolución Cubana, aunque recién declarase su carácter socialista dos años después, jugaba un rol destacado. Agosti redoblará así la apuesta, criticando al nacionalismo reaccionario y conservador su falta de planteos sobre el fenómeno imperialista y reclamará ese remoto antecedente para el PCA:

El hecho de cultura que implicaba el reconocimiento del imperialismo como factor deformante de la vida nacional no aparece ni por asomo demagógico en los planteos del nacionalismo aristocrático de 1930. Dos años antes, un congreso del Partido Comunista, con alguna imprecisión todavía, destacaba las condiciones particulares del fenómeno social argentino, caracterizado por la preponderancia del latifundio y la supeditación al imperialismo. ${ }^{20}$

Atento siempre a los aspectos culturales que en muchas oportunidades lo harán recurrir a Gramsci, y continuando con el mismo planteo, analiza el papel histórico que jugó el nacionalismo y arribará a una formulación de la "cuestión nacional" casi calcada de Hernández Arregui —a quien cita puntualmente varias veces - y otros pensadores de la izquierda peronista, quienes identifican dos tendencias diametralmente opuestas: un

\footnotetext{
${ }^{19}$ La reconstrucción del trabajo intelectual y político de Villanueva, un periodista y escritor de provincia que hizo importantes aportes en el plano cultural de las izquierdas, constituye una deuda a saldar. La dispersa obra del entrerriano fue compilada en tres tomos por la Universidad Nacional de Entre Ríos (UNER) en 2010. Entre sus trabajos más importantes en este sentido podemos mencionar el libro Crítica y pico. Sentido esencial del Martín Fierro (1945) o los artículos "La poética de Echeverría" (1951) y "La literatura de mayo" (1960), entre otros.

${ }^{20}$ AGOSTI, Héctor P. Nación y cultura, Buenos Aires, Centro Editor de América Latina, 1982, págs. 213214.
} 
nacionalismo reaccionario y un nacionalismo revolucionario. ¿Cuál hubiera sido la lectura de los comunistas ante la irrupción del peronismo, al cual catalogaron entonces como naziperonismo, contando en su acervo teórico con esta importantísima distinción? Difícil de establecer. Pero lo cierto es que, sin hacer menciones explícitas a ese hecho, el planteo deja entrever un reposicionamiento y abre la puerta a una comprensión distinta del fenómeno. Lejos de ubicar el peronismo bajo la categoría de nacionalismo revolucionario, y cuestionando aún el carácter "declamatorio" de su antiimperialismo, admite la posibilidad de que elementos de esta corriente ideológica jueguen en la historia un rol progresivo. El nacionalismo, entonces, sólo es legítimo como "sentimiento nacionalista", cuando va unido a una voluntad popular, mientras que las "formaciones de apelativo nacionalista" que sólo evocan elogios metafísicos hacia el pueblo constituyen su falsificación. Aun con sus errores y limitaciones, el mérito significativo de la generación intelectual de 1930 será haber vuelto la mirada hacia los problemas del país y afirmar una impronta nacional en la literatura:

Esa vuelta a lo nacional —a lo auténtica y entrañablemente nacional — significa un doble apartamiento del liberalismo, entendido como disgregación cosmopolita, y del nacionalismo, comprendido como enceguecida nostalgia de nuestro remoto origen hispánico. $^{21}$

A la par que va sentando las bases de esta lectura histórica, Agosti se recuesta en el marxismo y defiende su interpretación no como un giro producto de nuevos sucesos y lecturas, sino como una fiel extracción de los supuestos ya presentes en los textos clásicos de esa corriente. De esta forma, tras señalar que "el nacionalismo de la clase obrera es de naturaleza diversa al que pudieron sostener los grupos dominantes", criticar la incomprensión liberal de ese hecho y reafirmar, a su vez, el carácter internacionalista de la lucha obrera que "la vincula a las parejas luchas de los demás pueblos del mundo", el autor de El mito liberal disipará la creencia que considera incompatibles al marxismo y el nacionalismo, atribuyéndola a una simple "manifestación de ignorancia". Allí da un paso más y señala la posición que definiría a los comunistas:

Somos nacionales pero no nacionalistas. Y es esto: repudiamos el cosmopolitismo sin alma y sin fronteras que quisiera abolir las diferencias nacionales en nombre de la universalidad de la cultura, pero no nos cerramos tampoco a cal y canto a las comunicaciones con los demás pueblos, porque en esa internacionalización de los intercambios reside justamente el proceso universal de la cultura como un todo fluyente que busca su general equilibrio. ${ }^{22}$

Tras estas consideraciones iniciará un pasaje polémico contra los grupos vinculados al peronismo, pero también contra liberales como Sabato, quienes a su criterio habían encarado una "ofensiva ideológica" cuyo objetivo era demostrar que en 1945 se había iniciado en la Argentina una revolución. "No es preciso colocarse en la sobriedad de la interpretación marxista-leninista para comprender que no ha habido en este país una revolución", se responderá luego, aunque paradójicamente resulte éste uno de los tópicos

\footnotetext{
${ }^{21}$ Ibídem, pág. 247

${ }^{22}$ AGOSTI, Héctor P. El mito liberal, Buenos Aires, Procyón, 1959, págs. 32-33.
} 
donde Agosti más se recueste sobre las interpretaciones ortodoxas del comunismo respecto a cómo debía ser la revolución en la Argentina: agraria y antiimperialista, con el partido de la clase obrera a su cabeza. El hecho de apoyarse en "amplias masas populares" no confiere a su criterio carácter revolucionario a ningún movimiento, aunque reconocerá en el caso del peronismo el "anhelo de justicia social" que impulsó a los obreros a encuadrarse en ese movimiento. Lo que hubo entonces, a criterio de Agosti, fue un "desplazamiento relativo de las clases dominantes", donde quedaron de lado las fuerzas terratenientes-burguesas y comenzaron a prevalecer las fuerzas burguesas-terratenientes, no rozando así las estructuras fundamentales del país. De todos modos, valorará la toma de conciencia de los trabajadores peronistas, quienes a su criterio constituyen la "base y levadura de la auténtica revolución agraria y antiimperialista, capaz de solucionar nacionalmente los problemas de esta etapa", aunque advierta que para ello deberán librarse de "mecanismos ideológicos contradictorios de su impulso de clase"23. Esto es, aunque no lo aclare, librarse de la conducción de Perón y sus cuadros burocráticos. Los acontecimientos posteriores terminarían mostrando que, lejos de apartarse de su influjo, los trabajadores y luego amplios sectores medios fueron afirmando cada vez con mayor fuerza su lealtad a Perón.

\section{¿Qué es la izquierda?}

A partir de 1959 la confluencia de múltiples factores generó un escenario donde se alcanzaría tal vez el punto más alto en la producción intelectual de todas las izquierdas, cuyos debates e intercambios no siempre amistosos se multiplicaron a través de libros, revistas partidarias y culturales, publicaciones diversas e intervenciones públicas. Al problema suscitado alrededor del peronismo, tópico ordenador de todas las discusiones en aquél período, se sumaron como temas de análisis la capitulación de Frondizi (y con ella la decadencia de una determinada forma de pensar la izquierda) y la Revolución Cubana. Los matices que apenas distinguían a los pensadores de izquierda cercanos al peronismo poco a poco comenzaron a acentuarse, y entre ellos tuvo lugar una polémica que fue más allá del terreno intelectual para interrogarse cuál debía ser el papel de esa corriente ideológica que venía creciendo y extendiéndose en el último lustro.

Atendiendo a las distintas clasificaciones que intentaron describir con precisión y arrojar luz sobre estas tendencias que se desarrollaban por fuera de los partidos de izquierda clásicos, presentadas muchas veces indistintamente a pesar de sus diferencias, creemos necesario señalarlas en base a un criterio propio que las ordene al menos provisoriamente.

a) Aunque haya sido Hernández Arregui quien se atribuyó la paternidad del término ${ }^{24}$, y no esté incluido aquí, el grupo de la Izquierda Nacional es posiblemente el más distinguible de ellos, por sus límites menos imprecisos y su relativa persistencia como corriente. De orígenes trotskistas, sus antecedentes se remontan al menos hasta las publicaciones Frente Obrero y Octubre (1945), luego a la formación del Partido Socialista de la Revolución Nacional (1953) y algunos años después a la

\footnotetext{
${ }^{23}$ Ibídem, págs. 68-75

${ }^{24}$ HERNÁNDEZ ARREGUI, Juan José. La formación de la conciencia nacional. Buenos Aires, Ediciones Continente, 2011, pág. 369.
} 
fundación del Partido Socialista de la Izquierda Nacional (1962). Sus conexiones con otros grupos trotskistas, sin embargo, son más remotas ${ }^{25}$. La figura más influyente de este sector fue Jorge Abelardo Ramos, aunque no fue parte de sus formaciones iniciales.

b) Atendiendo a las definiciones de $\operatorname{Kohan}^{26}$, podemos identificar un Nacionalismo Revolucionario, cuyos principales exponentes fueron John William Cooke y Rodolfo Puiggrós, ambos - a diferencia del primer grupo- parte activa del gobierno peronista. En el caso del primero se destaca su labor como diputado, mientras que el segundo se sumará tras su ruptura con el PCA, desde una labor militante e ideológica.

c) Un Nacionalismo Popular o Nacionalismo de Izquierda encarnado en la figura de Hernández Arregui, quien hasta entonces había alternado su labor académica con un interrumpido empleo público en el gobierno peronista y luego con la crítica literaria en Radio del Estado, antes de publicar su primera gran obra tras la caída de Perón. Este pensador creía que la "izquierda nacional" debía constituir una tendencia ideológica al interior del peronismo, y no un partido separado. A pesar de su sólida formación filosófica y haber sido discípulo del marxista italiano Rodolfo Mondolfo, posiblemente sea él quien mayores deudas intelectuales contrajo con los nacionalistas populares de F.O.R.J.A., como Jauretche y Scalabrini Ortíz ${ }^{27}$. Sus planteos alcanzarán una importante difusión en la juventud de los 60, influyendo decisivamente a intelectuales como Rodolfo Ortega Peña y Eduardo Luis Duhalde.

d) En otro lugar pueden señalarse las formaciones de izquierda más lejanas a una identificación con el peronismo, donde se hallarían por ejemplo Milcíades Peña y Silvio Frondizi. Si bien excede los propósitos de esta rudimentaria categorización, es necesario destacar que aquellos grupos merecerían a su vez una distinción más precisa entre sí, que haga justicia con su historia.

e) Por último, podemos identificar una Nueva Izquierda intelectual, que se expresó a través de distintas publicaciones culturales y políticas, aún en formación, y cuyos miembros eran de una generación algunos años más joven que las mencionadas anteriormente $^{28}$.

Como puede apreciarse en el título de este trabajo, hemos utilizado la categoría más amplia de "izquierdas peronistas" (en un elástico plural) para agrupar a las tres primeras formaciones de esta clasificación. Sin desconocer las diferencias señaladas anteriormente, a los fines de reconstruir algunos debates creímos conveniente privilegiar sus rasgos comunes, entre los cuales resalta la reivindicación de la experiencia peronista y una postura muy crítica de las izquierdas tradicionales, sin ignorar la relativa autonomía del primer

\footnotetext{
${ }^{25}$ Véase GALASSO, Norberto. La Izquierda Nacional y el FIP. Buenos Aires, Centro Editor de América Latina, 1983.

${ }^{26}$ KOHAN, Néstor. Ni calco ni copia, op. cit.

${ }^{27}$ HERNÁNDEZ ARREGUI, Juan José. "FORJA y la lucha popular por la liberación nacional (La 'década infame')", en La formación de la conciencia nacional, op. cit., Capítulo IV.

${ }^{28}$ Para un análisis de esta tendencia véase TERÁN, Oscar. Nuestros años sesenta. Buenos Aires, Siglo XXI, 2013.
} 
grupo (con Ramos a la cabeza) que propició en distintos momentos la conformación de un partido independiente para apoyar al peronismo.

Durante la década que estuvo en el poder, el peronismo pudo disputarle espacios y restarle legitimidad al PCA y otras izquierdas en los sectores obreros, mientras aquellos seguían hegemonizando ampliamente el ámbito cultural e intelectual. Ese cuadro más o menos estable fue modificándose tras el golpe y la proscripción que pesaba sobre el peronismo, al tiempo que sus intelectuales pasaron a ocupar el lugar de relativo privilegio que les había sido negado anteriormente. Esta situación no pasó desapercibida para los dirigentes y actores culturales del PCA, que comenzaron a recoger los cuestionamientos que les efectuaban y a propiciar la producción de material crítico capaz de dar respuesta a esas objeciones, tanto para polemizar con sus adversarios de las nuevas izquierdas como para ordenar discursivamente a las filas partidarias. En ese contexto, Cuadernos de cultura aprovechó su ejemplar número 50 para poner en circulación un número especial titulado ¿Qué es la izquierda?, editado en coincidencia con un nuevo aniversario de la Revolución Rusa, pero cuyo eje vertebrador no respondía a una efeméride internacional sino a necesidades del presente argentino:

Nos ha parecido, pues, que más que un número habitual de recordación, destinado a valorar el esfuerzo portentoso del primer país socialista del mundo, era oportuno confrontar, frente a las realidades del marxismo viviente, las distintas manifestaciones con que suele presentarse entre nosotros la llamada neoizquierda. ${ }^{29}$

Con un objetivo explicitado desde sus primeras páginas, se buscaba allí dar respuestas a la proliferación de intervenciones realizadas por los representantes de las diversas izquierdas desarrolladas por fuera de los partidos tradicionales, pero sobre todo a la encuesta realizada por Carlos Strasser a exponentes de aquellas nuevas tendencias ideológicas, publicadas como libro el año anterior ${ }^{30}$, donde un denominador común de casi todos los entrevistados era la crítica al PCA. De esta forma, el partido convocará a algunos de sus más destacados intelectuales para realizar la respuesta colectiva: Ernesto Giudici y Agosti, los escritores de mayor trayectoria y renombre, junto al joven discípulo Juan Carlos Portantiero, Samuel Schneider y Mauricio Lebedinsky. La propensión al diálogo y heterodoxia de los primeros tres ${ }^{31}$ da lugar en este caso a un cierre de filas y defensa rígida de la actuación partidaria, que se diferencia de las producciones más abiertas que cada uno de ellos venía realizando. La defensa de la Unión Soviética, la crítica al rol progresista asignado al Ejército por algunos pensadores, la "idealización del obrerismo de Perón" 32 y la atribución de haber sido los primeros en elaborar una teoría que contemple el problema del

\footnotetext{
29 "Claridad sobre la izquierda", editorial de Cuadernos de Cultura, número 50, noviembre-diciembre de 1960. Esta edición saldría a su vez tres meses más tarde como una publicación independiente: AA.VV. ¿Qué es la izquierda? Buenos Aires, Editorial Documentos, febrero de 1961.

${ }^{30}$ Ese trabajo coordinado por Strasser se llamó Las izquierdas en el proceso político argentino.

${ }^{31}$ Cabe recordar que la intensificación de algunas diferencias lo llevarán a Portantiero a romper con el partido cuatro años después, mientras Giudici lo hará pero recién en 1973. De todos modos, no es recomendable ni es nuestra intención equiparar heterodoxia a ruptura ni proyectar desavenencias posteriores en debates del pasado.

${ }^{32}$ GIUDICI, Ernesto. “Neocapitalismo, Neosocialismo, Neomarxismo”, en AA.VV., op. cit., pág. 33.
} 
imperialismo, entre otros, son los rasgos comunes de las diferentes intervenciones. La conformación de un partido de la "izquierda nacional" ya comenzaba a ponerse en debate desde las páginas de El Popular, Política y otras publicaciones, y este hecho no pasó desapercibido para los intelectuales comunistas. Esta fundación, continuadora del Partido Socialista de la Revolución Nacional (PSRN) nacido en 1953 con la venia de Perón, finalmente agruparía en 1962 a una minúscula parte de la nueva tendencia ideológica, reunida en torno a Ramos. Aquel hecho marcará las profundas diferencias entre sus integrantes y acentuará sus matices, aunque hasta entonces las confluencias eran importantes y el "marxismo nacional" o "izquierda nacional" era visto como un bloque más o menos homogéneo, que el propio Agosti buscaba impugnar en conjunto:

Este marxismo nacional, o esta izquierda nacional, exagera unilateralmente los costados nacionales específicos (cuando no los desfigura o los adultera), olvida la existencia del mundo socialista como presupuesto concreto de liberación nacional, quiere inventarse a veces un tercer campo, fanfarronea con su extremismo de izquierda para sucumbir, finalmente, ante las limitaciones del nacionalismo burgués de El Popular puede mostrar hasta dónde se alarga y hacia dónde se proyecta esa operación confusionista. ${ }^{33}$

Desde las páginas de Política, Ramos y Hernández Arregui responderán a las formulaciones esbozadas por los intelectuales comunistas en ¿Qué es la izquierda? Mientras el primero arremete contra el PCA por su incomprensión del peronismo, calificándolos como habitualmente lo hacía de stalinistas y augurándoles un "insignificante porvenir", el segundo defiende a la izquierda nacional como un movimiento que parte de la comprensión del carácter revolucionario del peronismo, emparentando sus luchas con los movimientos de liberación de otros países y sin privarse de criticar a los autores de la obra colectiva:

Nos reservamos el derecho de contestarle a Ernesto Giudici que en el mencionado número falsifica las tesis de la izquierda nacional. En cuanto al señor Samuel Schneider, alto ejemplo de indignidad crítica, sólo le diremos que si todo gran hombre tiene su enano, Héctor P. Agosti tiene sus enanitos, siendo el más destacado el tal Schneider. En cuanto a H. P. Agosti, cada día está más nacional. Enhorabuena. $^{34}$

El autor de La formación de la conciencia nacional ya le había dedicado varias páginas a Agosti, destacando su giro nacional y criticando a su vez los residuos liberales de su pensamiento. Desde el punto de vista teórico sus coincidencias eran importantes, posibilitando intercambios fértiles entre ambos autores ${ }^{35}$, aunque la posición respecto al peronismo seguía distanciándolos.

\footnotetext{
${ }^{33}$ AGOSTI, Héctor P. "La 'crisis' del marxismo”, en AA.VV., op. cit., pág. 60.

34 HERNÁNDEZ ARREGUI, Juan José. "Izquierda Nacional y realidad argentina”, Política, 1961, en MASSHOLDER, Alexia, op. cit., págs. 258-259.

35 Para la reconstrucción de este debate véase GERLO, Martín. "El debate Hernández Arregui-Agosti. Peronistas y comunistas en la construcción de un ideario nacional y popular”, en Revista Izquierdas, $\mathrm{N}^{\circ} 18$, Santiago de Chile, abril de 2014 y MASSHOLDER, Alexia. 'Las lecturas sobre lo 'nacional'. Un posible
} 


\section{La tesis comunista del "giro a la izquierda"}

El ocaso del gobierno de Frondizi será el escenario de un inédito acercamiento entre el peronismo y el PCA, que propiciará en las elecciones provinciales de marzo de 1962, luego anuladas por el mandatario radical, su apoyo a los candidatos avalados por el proscripto movimiento popular. Dos artículos de Agosti escritos ese año testimonian su punto de vista sobre aquellos acontecimientos, que calificará como "el final de un ciclo histórico en la vida argentina" que da lugar sólo a dos posibles salidas: una nueva dictadura o un gobierno verdaderamente popular con proyección revolucionaria ${ }^{36}$. Más allá del desbordado optimismo que emanaban estas consideraciones, sucedidas por un cuadro mucho más complejo que el pronosticado por Agosti, el análisis de la situación por parte de uno de los más destacados intelectuales comunistas documenta la radicalización de los sectores obreros y medios que despertaron el entusiasmo de sus filas partidarias. Sin dejar de lado su calificación del peronismo como movimiento burgués incapaz de conducir la lucha de la clase obrera, distinguirá sus rasgos salientes en los diferentes momentos históricos:

En sus elementos fundamentales, el peronismo-1962 se presenta así como algo diferente no sólo del peronismo-1955 sino también del peronismo-1946, y esa calidad objetiva esboza perspectivas nuevas y fundamentales para cualquier planteo de futuro. Lo típico del peronismo-1962 no son sus dirigentes sino su base de masiva impregnación obrera. ${ }^{37}$

Esas bases obreras, sin embargo, ya no eran para Agosti las mismas que protagonizaron las jornadas de 1945, sino que habían pasado "la prueba del gobierno ejercido en su nombre" y soportaron luego el "período libertador" y el frondizismo, que condujeron a su transformación en un "proletariado con firme instinto de clase". El paso siguiente dependía entonces de una "difícil misión a cargo de la vanguardia organizada del proletariado, el Partido Comunista", donde debían conjugar una doble tarea de "acción común y crítica ideológica". Este escenario abría, por consiguiente, "las perspectivas para un entendimiento real y orgánico de las masas populares" ${ }^{\text {,3 }}$. Pocas semanas después, en la introducción a un número especial de la revista Recherches internationales à la lumière du marxisme dedicado a América latina, Agosti volverá a elegir a la "izquierda nacional" como principal interlocutora de sus planteos y reafirmará, ante ese público lector extranjero, la tesis del "giro a la izquierda" del peronismo. En el artículo discutirá los postulados de los nuevos nacionalismos que conciben a América latina como un "único país" balcanizado por la acción imperialista durante el siglo XIX, debatirá las posibles y necesarias alianzas de clases y cuestionará abiertamente el anticomunismo de la "izquierda nacional" en determinados países de la región. En esa línea, volverá a disputarles a esos sectores la paternidad en la utilización del concepto de imperialismo, y alertará que junto a

diálogo entre Juan José H. Arregui y Héctor P. Agosti”, en Apuntes de Investigación del Cecyp, Año XVI, N 21, noviembre de 2012.

36 "Proceso de la actualidad", 5 de mayo de 1962, en Prosa política, pág. 153.

${ }^{37}$ Ibídem, pág. 167.

${ }^{38}$ Ibídem, pág. 170. 
un nacionalismo latinoamericano de faz progresista existe "un ala reaccionaria" 39 . Para los partidos comunistas de América latina será entonces imprescindible "precisar sus relaciones con el movimiento nacionalista" ${ }^{", 0}$, entre los cuales el peronismo se presenta como uno de los más importantes.

Es indudable que los avances del socialismo y la victoria de la Revolución Cubana, como primera revolución auténticamente transformadora del continente, determinan radicales transformaciones en la actitud mental y política de las masas populares, obligando a ciertos caudillos nacionalistas a encarar la ampliación social de sus antiguos programas, como es el caso de Perón, cuyo "giro a la izquierda" inspira, a su turno, desplazamientos fundamentales en toda la política argentina. ${ }^{41}$

Cabe destacar que la Revolución Cubana había despertado el entusiasmo de muchos intelectuales peronistas, entre los cuales se destaca Cooke, que viajó a la isla en 1961 y desde allí mantuvo correspondencia con Hernández Arregui, a quien entre otras cosas le solicitó que le haga llegar sus libros para darles difusión. El ex diputado peronista verterá apreciaciones similares a las de Agosti pero de signo inverso: la Revolución Cubana había hecho ver "con claridad los problemas del peronismo" ". Lo cierto, más allá de la apreciación diferente, es que desde los dos sectores reconocían el influjo entre ambos fenómenos políticos.

Tras aquella descripción, continuadora de los lineamientos generales del PCA durante las elecciones de 1962 y tras el golpe contra Frondizi, Agosti sienta las bases de cuál deberá ser a partir de entonces el programa de los comunistas.

Lo singular del movimiento peronista, con poderosas raigambres en la clase obrera, es que proviniendo ideológicamente del nacionalismo burgués y, por lo tanto, de la conciliación de clases, va evolucionando en sus sectores más esclarecidos hacia las posiciones de la lucha de clases y aún hacia la admisión del socialismo, lo cual permite al Partido Comunista formular la perspectiva práctica de la creación de un gran partido obrero de masas, fundado en los principios del marxismo leninismo. ${ }^{43}$

Luego de trazar este panorama, el autor de Nación y cultura alertará sin embargo sobre algunos de los prejuicios recurrentes respecto a los partidos comunistas que realiza la "izquierda independiente", que opone sus ideas como parte de un producto nacional que se contrapondría a las ideologías "importadas", es decir, al marxismo leninismo. A su vez, estas tendencias proclamarían una tercera posición, renegando de la lucha de clases y planteando posibles alianzas con sectores vacilantes de la burguesía. La disputa con esos sectores no era exclusivamente parte de un enfrentamiento doctrinario, sino que lo que se

\footnotetext{
39 “Presentación de América Latina”, en Prosa Política, op. cit., Págs. 137-145.

${ }^{40}$ Ibídem, pág. 148.

${ }^{41}$ Ibídem, pág. 149.

${ }^{42}$ La carta de Cooke a Hernández Arregui, fechada el 28 de septiembre de 1961, está recogida en COOKE, John William. Obras completas. Tomo III. Buenos Aires, Colihue, 2009.

43 “Presentación de América Latina", op. cit., pág. 149.
} 
debatía era "la hegemonía real de la clase obrera y su partido marxista leninista en la revolución antiimperialista"44.

\section{Conclusiones}

El crecimiento cada vez mayor del peronismo durante los siguientes años inclinará definitivamente la balanza en su favor, coincidiendo con un proceso de resguardo en la ortodoxia que atravesará el PCA tras la expulsión de algunos sectores juveniles del partido. Aunque no fue ése el único momento histórico en el cual el comunismo se acercó al peronismo, y aun cuando siguió mirando con cierto recelo y desconfianza su arraigo identitario en la clase obrera, aquel período de agitadas jornadas políticas en el plano nacional e internacional marcó uno de los puntos de comprensión mutua tal vez más significativos. En esa línea, en este trabajo buscamos demostrar que ese cruce e intercambio entre los dos movimientos que se disputaban la representación de la clase obrera fue acompañado por elaboraciones y reelaboraciones teóricas que sentaban las bases para un entendimiento que trascendía lo coyuntural, siendo Agosti el intelectual comunista más importante en ese sentido. Como lo adelantábamos en la introducción, consideramos que ciertas categorizaciones rígidas, herederas de los fervorosos debates que tuvieron lugar en aquellos años, no favorecen un acercamiento más abierto a los aportes que realizaron pensadores de tradiciones políticas diferentes pero con importantes coincidencias teóricas. En este sentido, nos parece que el estudio del Pensamiento Nacional, que en la Argentina aparece ligado a pensadores de izquierda o nacionalistas populares cercanos al peronismo, se vería sumamente enriquecido si ensanchara sus horizontes buscando los aportes de otras tendencias populares y marxistas, de las cuales el comunismo sólo es una de ellas, discerniendo la crítica a la conducta de cierta dirección partidaria de las elaboraciones llevadas a cabo por intelectuales, militantes y dirigentes de menor poder en las estructuras partidarias. Propiciando un acercamiento basado en este enfoque, a nuestro juicio se abrirán algunas nuevas perspectivas para el estudio de las izquierdas en la Argentina de la segunda mitad del siglo XX, en el cual, sin forzar coincidencias allí donde no las hubo, sí podrán percibirse distancias tal vez más estrechas, elaboraciones fértiles e intercambios de significación.

\section{Bibliografía}

AA.VV. ¿Qué es la izquierda? Buenos Aires, Editorial Documentos, febrero de 1961.

AAVV. Cuadernos de cultura, Número 58, Buenos Aires, junio-julio de 1962.

AGOSTI, Héctor P. Echeverría, Buenos Aires, Editorial Futuro, 1951.

AGOSTI, Héctor P. Para una política de la cultura. Buenos Aires, Procyón, 1956.

${ }^{44}$ Ibídem, pág. 150. 
AGOSTI, Héctor P. Nación y cultura. Buenos Aires, Centro Editor de América Latina, 1982. (Edición original: 1959.)

AGOSTI, Héctor P. El mito liberal. Buenos Aires, Procyón, 1959.

AGOSTI, Héctor P. "Prólogo", en GRAMSCI, Antonio. Literatura y vida nacional. URL: www.gramsci.com.ar. (Edición original: Editorial Lautaro, Buenos Aires, 1960.)

AGOSTI, Héctor P. Prosa política. Buenos Aires, Editorial Cartago, 1975.

ALTAMIRANO, Carlos. Peronismo y cultura de izquierda, Buenos Aires, Siglo XXI, 2011.

ARICÓ, José M. La cola del diablo. Itinerario de Gramsci en América Latina. Buenos Aires, Siglo XXI, 2014.

COOKE, John William. "Carta a Juan José Hernández Arregui”, Obras completas. Tomo III. Buenos Aires, Colihue, 2009.

GALASSO, Norberto. La Izquierda Nacional y el FIP. Buenos Aires, Centro Editor de América Latina, 1983.

GRAMSCI, Antonio. Antología. Buenos Aires, Siglo XXI, 2013.

GURBANOV, A. y RODRÍGUEZ, S., "La compleja relación entre el Partido Comunista Argentino y el peronismo: (1943 - 1955)", Primer Congreso de Estudios sobre el Peronismo, Mar del Plata, noviembre 2008.

HERNÁNDEZ ARREGUI, Juan José. Imperialismo y cultura. Buenos Aires, Ediciones Continente, 2005. (Edición original: 1957.)

HERNÁNDEZ ARREGUI, Juan José. La formación de la conciencia nacional. Buenos Aires, Ediciones Continente, 2011. (Edición original: 1960.)

KOHAN, Néstor. Ni calco ni copia. Ensayos sobre el marxismo argentino y latinoamericano, Cuba. URL: http://lahaine.org/amauta/b2-img/nestor_calco.pdf

MASSHOLDER, Alexia. El Partido Comunista y sus intelectuales: pensamiento y acción de Héctor P. Agosti. Buenos Aires, Luxemburg, 2014.

PRADO ACOSTA, Laura. Héctor Agosti, el difícil equilibrio. Itinerario de un intelectual orgánico del Partido Comunista Argentino (1935-1963), Buenos Aires, Tesis de Maestría, Posgrado en Historia, Universidad de San Andrés, 2011.

TARCUS, Horacio. Diccionario biográfico de la izquierda argentina. De los anarquistas a la "nueva izquierda" (1870-1976). Buenos Aires, Emecé Editores S.A., 2007.

TERÁN, Oscar, Nuestros años sesenta. La formación de la nueva izquierda intelectual argentina. Buenos Aires, Siglo XXI, 2013. (Edición original: 1991.) 